\title{
Why relevance theory is relevant for lexicography
}

1 Introduction

2 The lexicographical process: the user's perspective

3 Relevance in the lexicographical process from the user's perspective

3.1 Extra-lexicographical pre-consultation phase
3.2 Intra-lexicographical consultation phase

3.3 Extra-lexicographical post-consultation phase

4 Implications for the lexicographer

5 Literature

5.1 Information tools

5.2 Other literature

Abstract: This article starts by providing a brief summary of relevance theory in information science in relation to the function theory of lexicography, explaining the different types of relevance, viz. objective system relevance and the subjective types of relevance, i.e. topical, cognitive, situational, socio-cognitive and affective relevance. It then shows, at the hand of examples, why relevance is important from a user perspective in the extra-lexicographical pre- and post-consultation phases and in the intra-lexicographical consultation phase. It defines an additional type of subjective relevance that is very important for lexicography as well as for information science, viz. functional relevance. Since all lexicographic work is ultimately aimed at satisfying users' information needs, the article then discusses why the lexicographer should take note of all these types of relevance when planning a new dictionary project, identifying new tasks and responsibilities of the modern lexicographer. The article furthermore discusses how relevance theory impacts on teaching dictionary culture and reference skills. By integrating insights from lexicography and information science, the article contributes to new ideas for both disciplines.

Keywords: relevance theory, function theory, information science, information tools, dictionary culture

\section{Introduction}

Relevance is a key concept in lexicography and has been studied at the theoretical level in detail in Information Science, as has been pointed out in Bothma/Tarp 2012. However, meta-lexicography has not addressed relevance theory as an aspect or constituent part of meta-lexicography. Bothma/Tarp (2012) have discussed relevance in 
lexicography in some detail, but the presentation is very theoretical and does not indicate clearly why it is important to address relevance theory in meta-lexicography. Although some examples are presented in Bothma/Tarp (2012), the article is very abstract and does not show clearly enough, through detailed examples, why relevance theory is relevant for lexicography. It also addresses only user perceptions in terms of different relevance types, without taking into account the role of the lexicographer in relevance judgements.

This article is based on function theory, which identifies four fundamental types of lexicographically relevant situations:

1. Communicative situations where a need to solve a communication problem may occur.

2. Cognitive situations where a need for knowledge may occur.

3. Operative situations where a need for instructions on how to perform a physical or mental action may occur.

4. Interpretive situations where a need to interpret and understand a sign, signal, symbol etc. may occur. (Bothma/Tarp 2012, 90)

For more details about function theory, the reader is referred to Bergenholtz/Tarp (2002; 2003), Fuertes-Olivera/Tarp (2014), Tarp (2008; 2015).

As stated above, relevance theory has been discussed in some detail in Bothma/ Tarp (2012). It is not the intention to repeat any of the detail of that article here, but only to provide a (simplified) summary of relevance theory to contextualise the following discussions. Readers interested in more detail about relevance theory are therefore referred to Bothma/Tarp (2012) and the references cited there, e.g. Cosijn (2003), Cosijn/Bothma (2005), Cosijn/Ingwersen (2000), Ingwersen/Järvelin (2005). The following is loosely based on Bothma/Tarp (2012), with further explanations and examples, also linking relevance theory and function theory.

Information Science distinguishes between objective and subjective relevance:

- Objective relevance is system-based (algorithmic or system relevance) and as such relates only to the e-environment.

- It is based on a match between information objects (such as a document, web site etc.) and search terms (in the case of text-based materials). The system matches the search term(s) to all information objects in the database. If the search term(s) occur(s) in the information object, the system indicates that there is a match (i.e., the information object is relevant) and lists the information object in the list of retrieved objects. Whether the object is useful in terms of the actual information need of the user is a different matter and there may be a number of factors that influence a user's perception about how relevant the data are and the user's information need may not necessarily be satisfied. (An information object - a term which corresponds to the term "data" in function theory - is any physical or digital entity in a variety of media that could provide potential information and could refer to documents, texts, web sites, images, audio, video and any other media. In non-text-based media, the user can obviously not enter search terms and the object itself, or part of the object, is used for the search. In this case, the 
retrieval is typically based on pattern matching. This type of retrieval will not be discussed further.)

- Objective relevance is standard in all search engine implementations - the system matches the search term(s) (or part of the search term(s) if truncation is used) to the documents in the database and then provides a list of all documents that match with the search term(s). Sophisticated relevance ranking algorithms are used to ensure that the "most relevant" documents move to the top of the lists. "This 'relevance ranking' algorithm usually takes many factors into account. Exactly what factors go into the relevance ranking process varies, but they include: use of keywords in titles, text, headings, etc.; popularity of the sites (how many and what kind of links within the larger site point to the page); quality of links leading out to other pages [...]; etc.” (Hock 2012, 303).

- Objective relevance is presupposed in the function theory, as it assumes that the user obtains data from the system based on the matching of the search term(s) with data in the database, based on the indexing schemata and algorithms found in the search engine, or in the data provided once a link is followed - the system "objectively" provides the results of the search or of clicking the link to the user on the screen.

- Subjective relevance is user-based; this implies that the user makes a subjective judgement of the relevance of the data based on his/her subjective perception of the relevance of the data to solve his/her information need in a given situation. The system therefore retrieves data based on search algorithms and presents the data to the user. In terms of the user's evaluation of the data in relation to his/ her information need, the data may or may not be relevant. Such subjective evaluations can be categorised under a number of different types of subjective relevance, namely:

- Topical relevance

-- If data are topically relevant, most (or the larger part) of the data deal with the specific information need in a given situation. Data may, however, only incidentally address this need and the larger part of the data may therefore be topically not relevant.

-- If a user searches the internet for data dealing with, for example, a detailed discussion of French aircraft used during the First World War (WWI), the search engine will present him/her with a very long list of "hits", all perfectly relevant at the system level, because the system matched the search terms with words/phrases which occur in the data. Not all data will, however, be equally relevant to the user's actual information need. Many of the "hits" will only incidentally deal with French aircraft of WWI (discussing, for example, inter alia German and British aircraft of this period, or comparing WWI and WWII aircraft) and the larger part of such articles may be topically not relevant to the user's information need.

-- Topical relevance is a description of the relevance of the content in relation to the information need. An article that includes data on algebra when the user has an information need related to geometry, or that includes an explication of German inflection when (s)he is writing a French text, will therefore be partially or even totally irrelevant at the topical level. 
- Cognitive relevance

-- If data are at the level of complexity the user requires solving his/her specific information need in a given situation, the data are indicated as cognitively relevant. However, data may be too complex or not complex enough. In such a situation, it would be classified as cognitively not relevant.

-- A document on quantum physics written for the expert, containing complex detail and mathematical formulae, will not be understandable to the average lay person and will therefore not be relevant at the cognitive level for a lay person in his/her specific user situation. Conversely, a general document aimed at a lay person will not solve the information need of the expert and such a document will be cognitively not relevant to the expert.

-- Cognitive relevance relates to the user in function theory, where the characteristics of the user are described in considerable detail; see Bergenholtz/Gouws (2007), Bergenholtz/Bothma (2011), Fuertes-Olivera/Tarp (2014) etc.

- Situational relevance

-- If the data presented to the user are relevant to the specific situation in which the user finds him-/herself, e.g. for completing a specific work task or leisure activity, the data are said to be situationally relevant. However, if the problem that the data address is not related to the specific situation, the data are said to be situationally not relevant.

-- If a farmer in the developing world needs information on how to exterminate a specific plant disease in his/her crop, and (s)he is presented with data on how to use sophisticated chemical products that are not available or affordable in his/her context, the data would be not relevant at the situational level. An indigenous knowledge solution may be much more relevant in the specific situation.

-- In function theory, each information need is contextually bound, i.e., it occurs in a specific user need situation and therefore relates to situational relevance. The function theory requires that only content relevant to a specific information need in a specific situation be presented to the user, e.g., in a text reception situation, the user does not need data relevant to text production and vice versa. Topical relevance is therefore an inherent feature of function theory, even though this has thus far not been discussed in the research literature.

- Socio-cognitive relevance

-- If the data which are presented to the user complies with the viewpoints, scientific paradigms etc. which are generally held in the community in which the data are to be used, the data are said to be socio-cognitively relevant. However, the data may not be applicable in a specific socio-cultural context and in such a situation the data would be socio-cognitively not relevant.

-- While being on holiday in a specific country, a user's need for information on the observation of religious holidays will be determined by the dominant religious customs of the country, and information about such customs in that specific country may not be socio-cognitively relevant in a secular country or a country with a different dominant religion. 
-- Socio-cognitive relevance relates to a match between the presuppositions of the content and those of the community in which the information is used, meta issues of context and content. As such, it links clearly to function theory as these meta issues are characteristics of content and context, both central to function theory.

- Affective relevance

-- Affective relevance (also called motivational relevance) may pertain to all the preceding relevance types and is not the ultimate subjective relevance. Data may thus be relevant at all the preceding levels of relevance, but if the user feels that the data are (for example) biased in terms of a specific theoretical or ideological framework, the user may be less inclined to trust or use the data in a specific situation.

-- A user's choice of information sources is very often closely linked to his/ her ideological convictions. This is especially clear in the case of the selection of, for example, television news stations and news papers, where a user may express a specific preference for left-/right-wing or moderate sources, depending on his/her own viewpoints.

-- In function theory, the user chooses a specific dictionary to obtain the data to solve his/her information need. Such a choice may be made based on the user's knowledge of different dictionaries, but the choice may also be much more subjective, and the user may select or avoid a specific dictionary because of the layout, fonts, colours etc. used in the dictionary, or the style of writing, search features etc. Affective relevance judgments therefore also play a role in function theory.

This section provided a brief introduction to function theory and relevance theory. It also shows how function theory could relate to relevance theory, even though these linkages have not thus far been pointed out or discussed in the research literature. Hereafter it will discuss the user and issues pertaining to relevance from a (traditional) lexicographical point of view in section 2. This is followed in section 3 by a detailed discussion of examples from various e-dictionaries to illustrate the different types of relevance in some detail. Thus far the role of the lexicographer is not addressed. In section 4, however, we will discuss the lexicographic process from the perspective of the lexicographer, and explain how relevance theory and the different types of subjective relevance could influence the decisions of the lexicographer in this process. Such decisions may also have implications for the technical design specifications of the database and these implications will also be dealt with. From the preceding discussions it will become clear that relevance and relevance theory should influence the lexicographer's decisions in terms of his/her view on the data (and the database, as well as preparing the data to be captured in the database) based on his/her perceptions of user needs in specific user situations. 


\section{The lexicographical process: the user's perspective}

The lexicographical process can be seen both from the lexicographer's point of view, i.e. the way dictionaries are conceived and produced, and from the user's point of view, i.e. how the dictionaries are used. The two types of process are interwoven and share several intersection points. Yet, as the basis of all lexicographical work is ultimately the user's needs, both the first and the second process can only be fully understood if they are taken into account from the user's perspective. In this section we will therefore have a closer look at the latter and then later return to the former.

The function theory (see previous section) does not only study the process taking place from the moment the actual user starts consulting a lexicographical tool to the time when the required information is retrieved from the data contained in this tool, i.e. the intra-lexicographical consultation process. It is also interested in the extra-lexicographical processes taking place immediately before and after consultation. The reason for this approach is two-fold: on the one hand, it is necessary to know in which situation the lexicographically relevant information needs occur in order to determine the nature of these needs; and on the other, it is absolutely necessary to evaluate the post-lexicographical process in order to establish an objective criterion for success or failure rather than the subjective type used by questionnaires and the like, cf. Tarp (2009). In this respect, a "normal" lexicographical process from the user's point of view comprises the following phases and steps, as stated in Bothma/Tarp 2012:

- an extra-lexicographical pre-consultation phase where a user with specific characteristics finding him- or herself in a specific context or situation:

- experiences an information need,

- becomes aware of the information need,

- determines whether this need is lexicographically relevant,

- and decides to start a lexicographical consultation;

- an intra-lexicographical consultation phase where the user:

- selects the relevant lexicographical information tool,

- accesses the relevant data,

- verifies that he or she has found the right data, i.e. relevant to the information need in question,

- $\quad$ and retrieves the needed information from the data;

- an extra-lexicographical post-consultation phase where the user:

- makes use of the retrieved information in order to solve a communicative or cognitive problem, to store it as knowledge, to perform a task or to interpret a sign, signal, symbol etc. (Bothma/Tarp 2012, 92-93)

Lexicography, as the science of dictionaries and similar information tools, is supposed to study all these phases and steps, in which relevance plays a central role for the process to proceed and be carried out with success.

In the extra-lexicographical pre-consultation phase, the user, once (s)he has experienced and become aware of the information need, has to decide 1) whether this need is lexicographically relevant, i.e. whether it may be solved through the consulta- 
tion of a lexicographical tool; and 2) whether it is relevant to actually consult such a tool, i.e. whether there are other more relevant types of information tools available. In this phase, relevance is solely related to the user's own criterion.

In the intra-lexicographical consultation phase, the user will first have to choose the lexicographical tool which (s)he considers relevant to solve the specific need, and which, in fact, should be relevant in order to do so. Then the user will have to access and verify the data which (s)he considers relevant, and which also should be so. And finally, the user has to retrieve the relevant information from these data. As can be seen, in this phase relevance is both related to the user's assessment of the tool and the data and to the tool and data themselves.

In the extra-lexicographical post-consultation phase, the user has to make use of the retrieved information in order to meet the specific need. Also in this case relevance plays a role, as the retrieved information should, in fact, be relevant for this specific purpose, both as perceived or assessed by the user (subjective criterion) and if it is tested by a third person by means of appropriate qualitative methods (objective criterion). The user could, for instance, be perfectly happy with the information retrieved without being aware that it is not adequate for his/her specific purpose. This could be a translational equivalent that did not fit into the text in the target language; or it could be a definition that may be appropriate in one context but not in the specific one in which the user experiences the need leading to the lexicographical consultation.

\section{Relevance in the lexicographical process from the user's perspective}

In section 2, we saw how the user's lexicographical process could be subdivided into three main phases, each of them including one or more steps. In this section, we will provide examples of how the various types of relevance express themselves in each of these main phases.

\subsection{Extra-lexicographical pre-consultation phase}

In the extra-lexicographical pre-consultation phase, the users have to take two important steps. The first is to define the need experienced in a specific situation and determine whether it is lexicographically relevant or not; and the second is to decide if they should initiate a lexicographical consultation. From the point of view of the user the two steps will most often appear interconnected, although they are of a slightly different nature. According to the function theory, a user need is lexicographically relevant when it is both a need for information, i.e. not a need for anything else, and a punctual need which can be solved through lexicographical consultation (in contrast 
to a global information need which can only be solved by studying other text types such as treatises, text books, etc.). The users, however, will in most cases not be aware of this theoretical criterion and will, instead, determine the nature of the need based upon their success, or lack of success, in previous contacts with lexicographical products when having similar needs; and the same criterion will also prevail when deciding whether or not to take lexicographical action. In both cases we have an example of affective relevance because it is based on the users' subjective preference and liking.

\subsection{Intra-lexicographical consultation phase}

\subsubsection{Selection of information tool}

In the intra-lexicographical consultation phase, the users need to take several decisions and actions where relevance plays a role. The first of these is the selection of the lexicographical tool to be consulted in order to get access to the data required to meet their information needs. This selection of a tool can take place in different contexts placed in a spectrum between two extremes: on the one hand, the context where only one dictionary is available to the user; and on the other hand, the one where an almost unlimited number of dictionaries is available. In the first of these contexts the users will, in fact, only have the choice between consulting or not consulting a tool which may be inappropriate in any case; whereas in the second context, the users will have a genuine choice and, therefore, the possibility of finding the most appropriate tool. The following reflections will be based on the hypothetical assumption that the users are selecting the information tool in the second context. As will be seen, all five types of subjective relevance can be observed in this selection phase although they are not employed equally by all users. We will look upon them one by one.

The first type of relevance which can be observed in the selection phase is affective relevance. Most users do not think about relevance theory or any other scientific theory when they have to choose a lexicographical tool. This, however, does not exclude that they base the selection on certain criteria, of which they are more or less conscious. The most simple - and probably also the most frequent - criterion applied is that the users simply like one tool and dislike another because of the size of a printed dictionary, the design and colour of its cover, the fonts and font sizes used, the structure of its articles, the design and layout of the webpage in an online dictionary, the lack of commercial publicity, as well as other external features and esthetical characteristics. A user could, for instance, prefer not to use some free online dictionaries because the screen appears overloaded with disturbing advertisements (e.g. the free online Macmillan Dictionary), although these dictionaries may be equally good at a topical, cognitive, situational, and socio-cognitive level. All this has basically to do with personal taste and individual preferences; as such, it is clearly an expression of affective relevance as defined in the introduction to this article. 
The second type of relevance observed in the selection phase is topical relevance. If users, for example, need assistance to understand English they will not select German dictionaries from Duden or Brockhaus but rather English ones from Oxford or Macmillan, inasmuch as English is the topic of their interest. When students of archaeology need explanations of specific terms, they will not choose the general Concise Oxford Dictionary of English but rather the specialised Concise Oxford Dictionary of Archaeology because the latter deals with the topic of their study. If one opens a dictionary portal like the Danish Ordbogen.com, one can simply introduce a word in the search field and then get a large number of articles from different dictionaries, or one could also, as indicated in Figure 1, specify which particular dictionary in terms of language or subject field one would like to consult. A similar choice between a general or a narrower subject-dependent search method is provided by the Oxford Reference (see Figure 2). Many other examples could be provided, all of them expressing topical relevance as a frequent selection criterion.
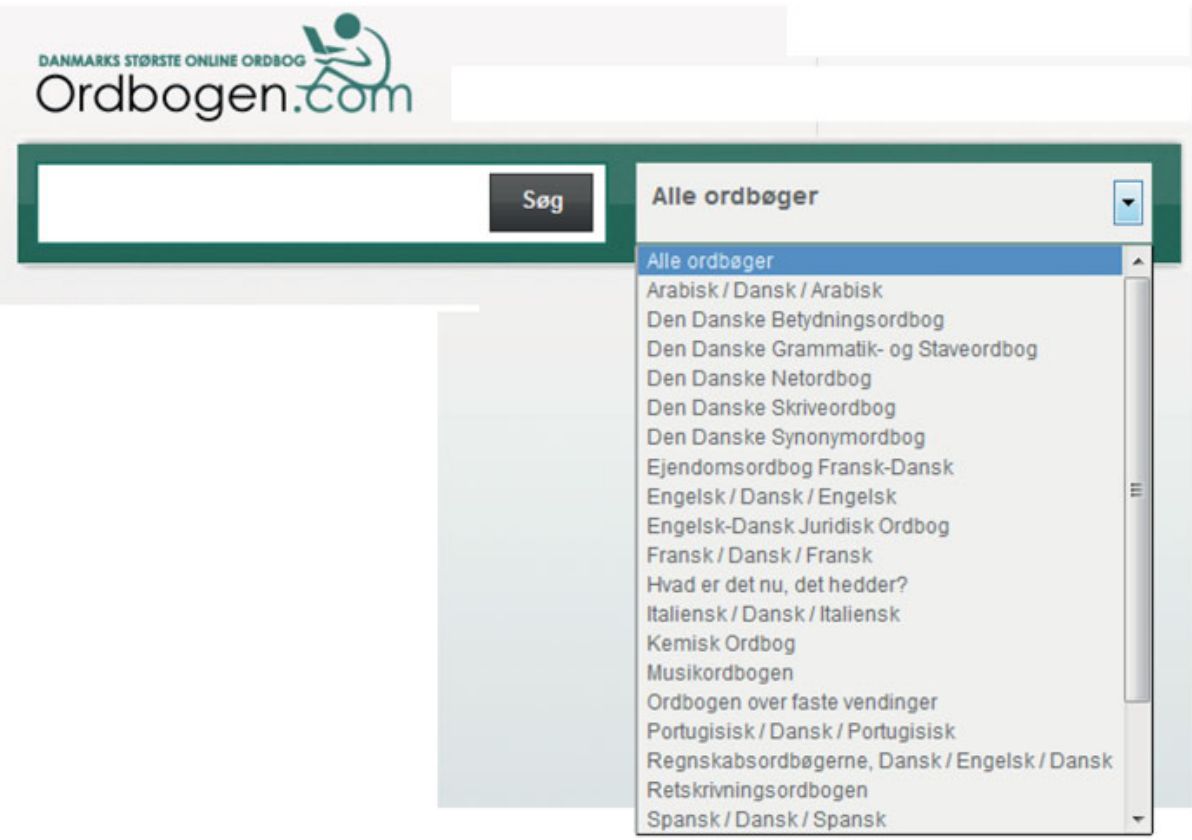

Figure 1: Web portal from Ordbogen.com 
About Whars New Subscriber Services contact Us Take a Tour Help

\section{Oxford Reference}

Personal Profle: Sign in or Create

Q

Dearch whin my subject specialzations: Select - A

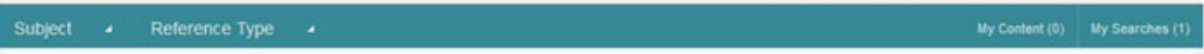

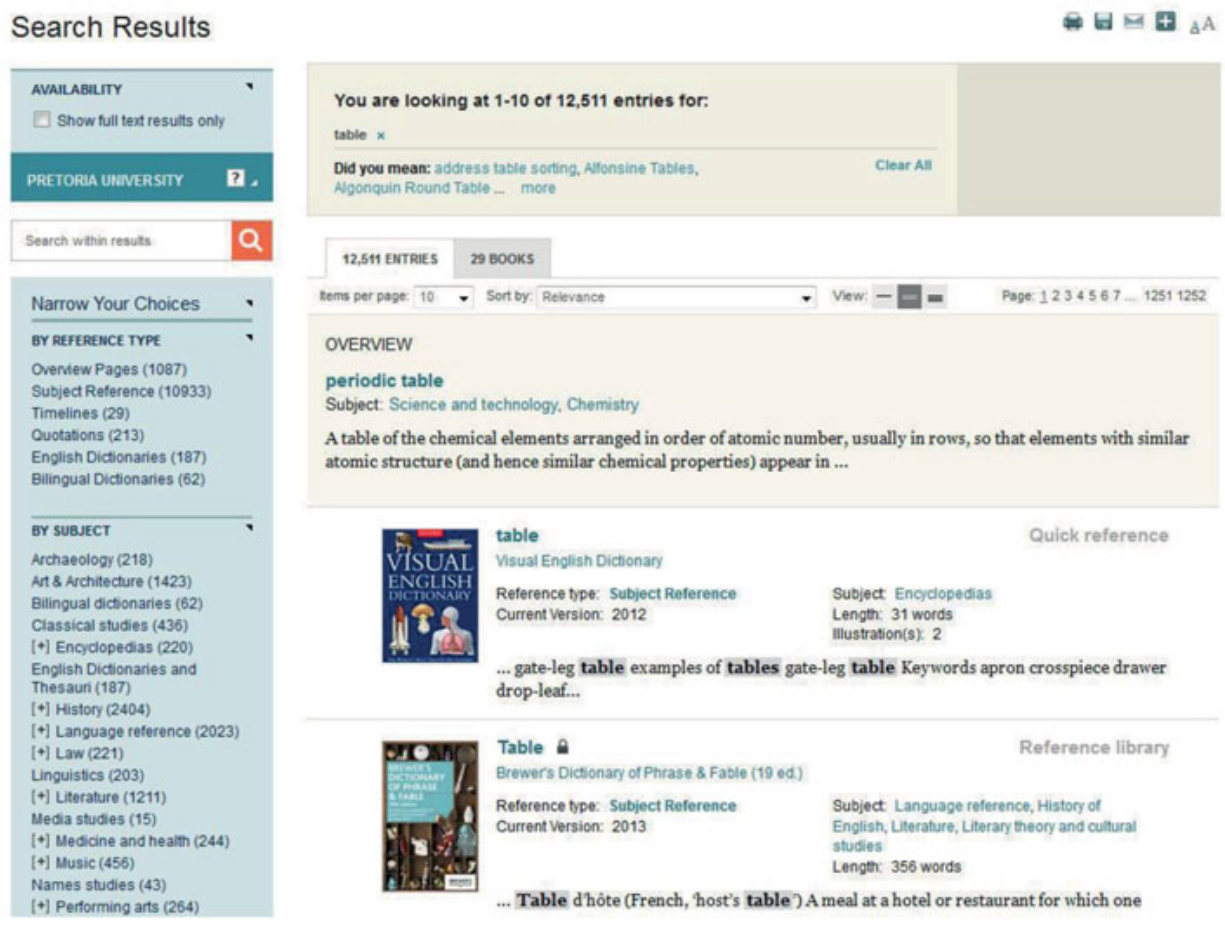

Figure 2: Web portal from Oxford Reference

The third type of relevance which can be observed in the selection phase is cognitive relevance. As the previous type of relevance, it is expressed in many ways. Whilst a first-year student of economics most often would choose to consult the Oxford Dictionary of Economics rather than the New Palgrave Dictionary of Economics when needing information concerning a certain topic related to economics, a top researcher or scholar within this field would probably prefer to do the opposite. Similarly, a university student of mathematics, in order to get relevant assistance, would not consult the Oxford Primary Illustrated Maths Dictionary, but rather the Concise Oxford Dictionary of Mathematics, whereas school children from the age of seven would be most happy with the former. Correspondingly, foreign learners of English at an intermediate proficiency level would prefer one of the famous Five Big or other similar dictionaries particularly designed to assist learners rather than consulting the Concise Oxford Dictionary of English or the Merriam-Webster's Concise Dictionary of English, both of 
which were primarily conceived to assist native speakers of English. When making all these choices, the users intend to find a dictionary addressed to their cognitive level in terms of foreign-language proficiency or subject-field knowledge. All are examples of selection based on the criterion of cognitive relevance.

The fourth type of relevance which also may influence the selection of an appropriate information tool is situational relevance. Lexicographically relevant information needs always occur in specific types of social context or situation such as text reception, production, translation and cognition, cf. Fuertes-Olivera/Tarp (2014). When users, for instance, experience problems related to English text production they will not get much help if they consult a dictionary only containing explications of the words, i.e. a dictionary designed to assist text reception; in order to get their specific needs fulfilled they will have to consult a dictionary furnishing lexicographical data on inflection, syntax, collocations, etc. If they look for maximum help, users will have to address dictionaries specifically designed to assist them when performing specific types of tasks. All this indicates that situational relevance is also a useful criterion in the selection phase. However, as many dictionaries - even electronic ones - are still designed for a broad group of users with needs occurring in various types of situation, users might have difficulties finding exactly the dictionary corresponding to their specific needs, and they may, therefore, consult dictionaries where they meet a combination of information overload and underload in terms of their specific needs. Due to this experience, many users will not be aware of the need to use situational relevance as a selection criterion, at least not with the required precision and exactness. This, of course, does not exclude situational relevance as an important criterion when selecting an appropriate information tool; yet it suggests that users may benefit from at least some lexicographical training and knowledge in order to take maximum advantage of the large number of dictionaries and other information tools made available to them on the Internet.

The fifth type of relevance relevant in the selection phase is socio-cognitive relevance. This is expressed in multiple ways. Let us take the example of a non-native speaker of English who is preparing a speech to a very formal public, e.g. when being granted the Nobel Prize, and consults a dictionary for assistance to write in an expressive and adequate style, then it is important that the dictionary indicates that some vulgar and low-style words which (s)he was considering to use are marked accordingly. Similarly, when students want to know something about modern economics, it would not be advisable for them to consult Malachy Postlethwayt's Universal Dictionary of Trade and Commerce from 1774, in which they will find a lot of interesting but also completely outdated information. Much more relevant would it be to consult the Oxford Dictionary of Economics in its fourth edition from 2012, or even better, its updated online version. In the same vein, if students, or anybody else, want to learn something specific about Marxist political economy in relation to a thesis or an oral presentation, then they should be referred to a dictionary based on this world view, and not one with a Keynesian or Neoliberal approach. Finally, if Danish or Chinese 
school children studying mathematics need to consult a dictionary in order to get cognitive assistance related to this subject, then it cannot be recommended that they use the South African Oxford Mathematics Dictionary, not only due to the language but also because it has been designed in accordance with a specific curriculum and method of teaching mathematics. All these examples show that socio-cognitive relevance is also a pertinent criterion in the selection of an appropriate lexicographical tool, at least in some cases.

So far we have looked at the selection of an information tool and related this phase to the five subjective criteria established by relevance theory, as it has been developed within information science. However, there is one additional subjective criterion applied by an increasing number of users of electronic dictionaries, and which does not fit into the five criteria treated above. The branch of information science dedicated to the finding and provision of data (called information objects) to their users, mostly - although not exclusively - deals with larger documents which the users then will study and work with during a certain period, hours, days, weeks, months, or even years. By contrast, in lexicography, most users will immediately make use of the data provided and subsequently, maybe even within a few seconds or minutes, return to the lexicographical tool for a new search in order to satisfy a new need, thus repeating the process a considerable number of times each and every day. Consequently, not only the quality of the data provided, but also the time it takes to obtain and handle them, becomes an important criterion of quality and, hence, increasingly relevant when selecting the most appropriate information tool. It is of absolute relevance to a busy user that a lexicographical search takes as little time as possible, i.e. only a few seconds or even less instead of various minutes, as it frequently happens, especially when the Internet connection is bad. The users will, therefore, have to judge not only the result of the search process but also this process and the information tool itself. In this respect, the usability and functionality of the information tool becomes a relevance criterion, at least in terms of lexicography, a criterion which could appropriately be called functional relevance.

In this section we have seen that users may employ a total of six subjective relevance criteria when selecting a lexicographical information tool. However, not all users will be in a position to handle all six criteria; some will only employ one (affective relevance) or a few. This is basically a question of dictionary culture, cf. Hausmann (1989) and Gouws (2013). The higher the dictionary culture, the more criteria will the user be able to apply; and the more criteria applied, the better the possibility of choosing the most appropriate information tool. This opens new perspectives for the learning and teaching of the so-called reference skills in the framework of a general lexicographical culture. We will come back to this question as part of the conclusions at the end of the article (see section 4). 


\subsubsection{Data access and verification}

Once the user has selected the appropriate information tool in terms of his/her information need (as discussed in the previous section), (s)he has to access the data and verify that the data are relevant in terms of his/her information need, as explained in section 2. In this section, we assume that the user selected an appropriate tool; if the tool is inappropriate, the possibility of accessing relevant data are extremely small and such options will not be discussed further.

The user may access data in e-dictionaries by means of different access methods, typically through various search interfaces or by means of various ways of displaying alphabetical lists and requiring the user to click through to the following levels of detail by following links. In the Algemeen Nederlands Woordenboek, the user is offered the option of both a simple search interface and a list of the alphabet. The word the user requires can be entered in the search box and, after pressing "Zoek" ("Search"), the user is immediately taken to the dictionary article. Alternatively, a user can click on the first letter of the word (s)he requires, which links to the first word in the dictionary starting with this letter; the user then scrolls down to find the word which is required, clicks on it and is linked to the relevant article in the dictionary. Both access routes are (partially) illustrated in Figure 3 below.

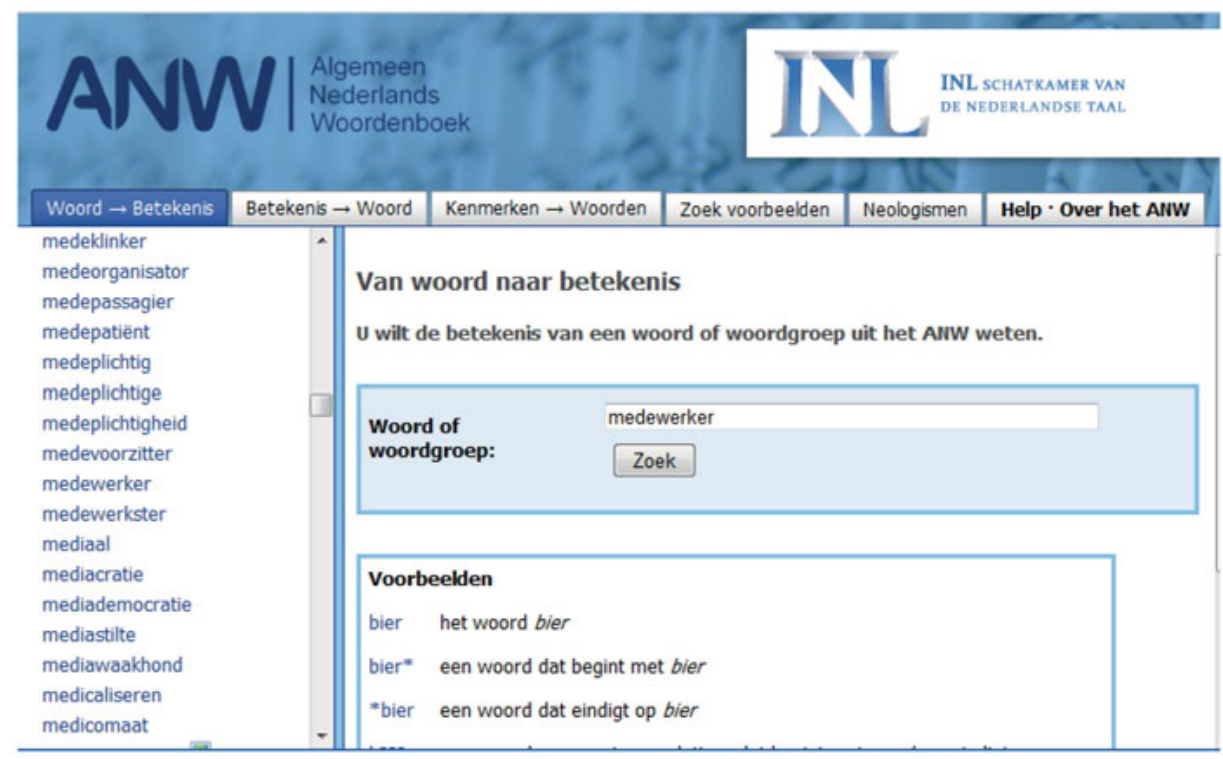

Figure 3: Access via different access routes in the Algemeen Nederlands Woordenboek

Both access routes result in the same data being displayed on the screen. In the linking option, the user follows a logical path predefined in the system and the system follows this path based on the clicking/scrolling actions of the user; eventually the 
user arrives at the correct lemma. In the search option, the system searches for the matching word based on the algorithms in the system and the lemma that matches the search term is displayed on screen. In both cases, the system decides "objectively" which data to display on screen and only these data are displayed. In terms of objective relevance, the data displayed on screen is relevant.

In relevance theory, relevance judgements usually refer to the user's evaluation of the content in relation to his/her information need, as discussed above. However, the choice of access route here depends on a subjective choice of the user. In this case, therefore, the choice relates to affective relevance - a user may prefer the one or the other method of access, not on the basis of the any of the subjective relevance types related to the content, but simply on what (s)he "likes" or "dislikes".

Depending on the amount of data included in the dictionary, a dictionary article displayed on screen may result in a total information overload, especially in many "national" or comprehensive dictionaries, such as is the case in many articles in the Woordeboek van die Afrikaanse Taal, the Oxford English Dictionary, Historische woordenboeken op internet, etc. (See also the "table" example from the OED in Bothma/Tarp (2012).) In these cases, most of the information would not be relevant in terms of the user's information need in a specific usage situation. For example, notes on the etymology or examples from the 14th to the 19th century are not required when the contemporary meaning of a word is required in a text reception situation. In such cases, the user may have to spend a considerable amount of time to wade through large amounts of data to find the data relevant in the specific situation, i.e. data that are topically, situationally and socio-cognitively relevant.

This problem may occur even in less comprehensive dictionaries, as in the following case. Kindle e-books are linked to a downloaded version of the Oxford Dictionary of English, and by selecting or clicking on a word, the user is provided with the first three lines of the dictionary article, with the option to link to the full article if the required data are not shown. At the system level, the data are relevant, because the system links the user to the lemma. Since it is an intermediate dictionary, the data are fairly easy to understand for a user with at least an average knowledge of English, and the entries tend to be cognitively relevant for such users. However, the data presented may not necessarily be relevant at other levels.

The linked dictionary is a multifunctional monolingual dictionary. Even though the focus is on providing a comprehensive list of meanings and senses of words, collocations etc., it does provide data that are not relevant in a text reception situation, such as pronunciation, origin of words (i.e., etymologies) etc. Such data are therefore not relevant at the situational level.

The system links to the first "hit" in the dictionary (and displays the first three lines of the dictionary article). This linking usually works very well and the data presented to the user very often are exactly the correct data to solve the specific text reception information need. However, this is unfortunately not always the case, as is evident from the numerous examples cited in Bothma/Prinsloo (2013). Four examples will suffice: 
- Linking does not distinguish between parts of speech, and regardless of the part of speech of the word in the text, it would link to the lemma, regardless of whether it is the correct part of speech, e.g., "dreams" (as the singular present tense of the verb), links to the noun, because the order in the dictionary in this case is "noun, followed by verb". The data are therefore irrelevant at the topical level.

- In the case of homographs, the first lemma is shown, and the user has to consult the full dictionary to find out what alternatives are available. The data shown originally may therefore be irrelevant at the topical level.

- Lack of morphological parsing results in strange links, e.g. "leaves" as the singular of the present tense of the verb "leave", links to the noun "leaf", indicating that it is the plural. The data presented to the user are evidently wrong and not relevant at the topical level.

- Some articles in the Kindle-linked dictionary are quite long, and phrases occur only at or close to the end of the dictionary articles. Kindle linking does not make provision for phrase linking, which implies that when the user is presented with the first three lines of data from the dictionary article, his/her information need cannot be satisfied; (s)he then has to go to the full dictionary article and, in many cases, scan or read through quite a number of screens of data to find the relevant data (if the specific data were taken up in the dictionary). In such cases, the data presented to the user are not relevant at the topical level.

In terms of the function theory, the full articles in the preceding cases may be relevant in a cognitive situation where the user may have a need for knowledge. However, if the user simply has a need for data in a text reception (or text production) situation, most of the data would be irrelevant at the situational level.

Some dictionaries, however, allow the user to filter the data based on the user need in a given situation. Some of the dictionaries developed at the Centre for Lexicography at the University of Aarhus and published by Ordbogen.com provide the user with the option to filter data based on an information need in a text reception, text production or cognitive user need situation, as is evident from the following examples in Figures 4 and 5.

From the examples in Figures 4 and 5 it is clear that the user has filtered the data in terms of his/her information need, and that quite different data are displayed to the user - all data that may be relevant in the specific user situation, and only these data. If the user had selected the "Know more about an expression" button, even more data than in Figure 5 would be added. This filtering obviously has implications for the construction of the database, as briefly mentioned below and in section 4.

In advanced search interfaces, users may have many more choices than simply typing a search term in a search box or following links, as in the example in Figure 6. 


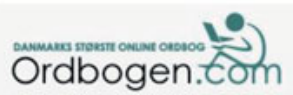

Kab privat Uddannelse Erhverv Downloads Support s Kontakt
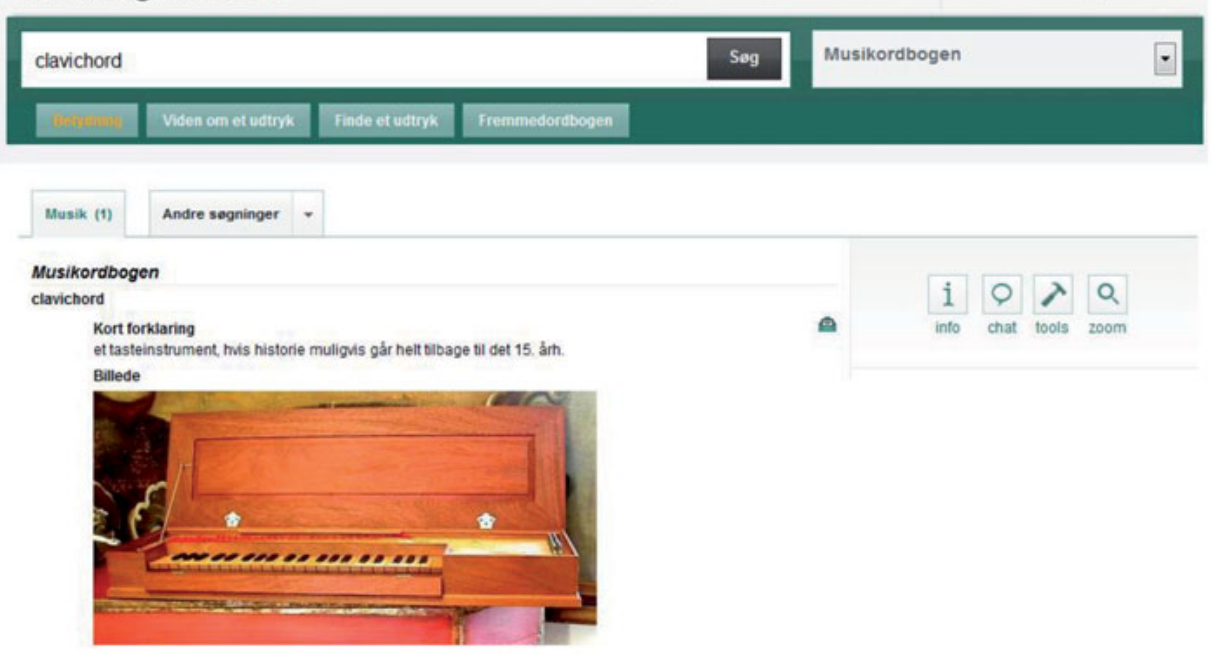

Figure 4: Text reception data from the Music Dictionary at Ordbogen.com
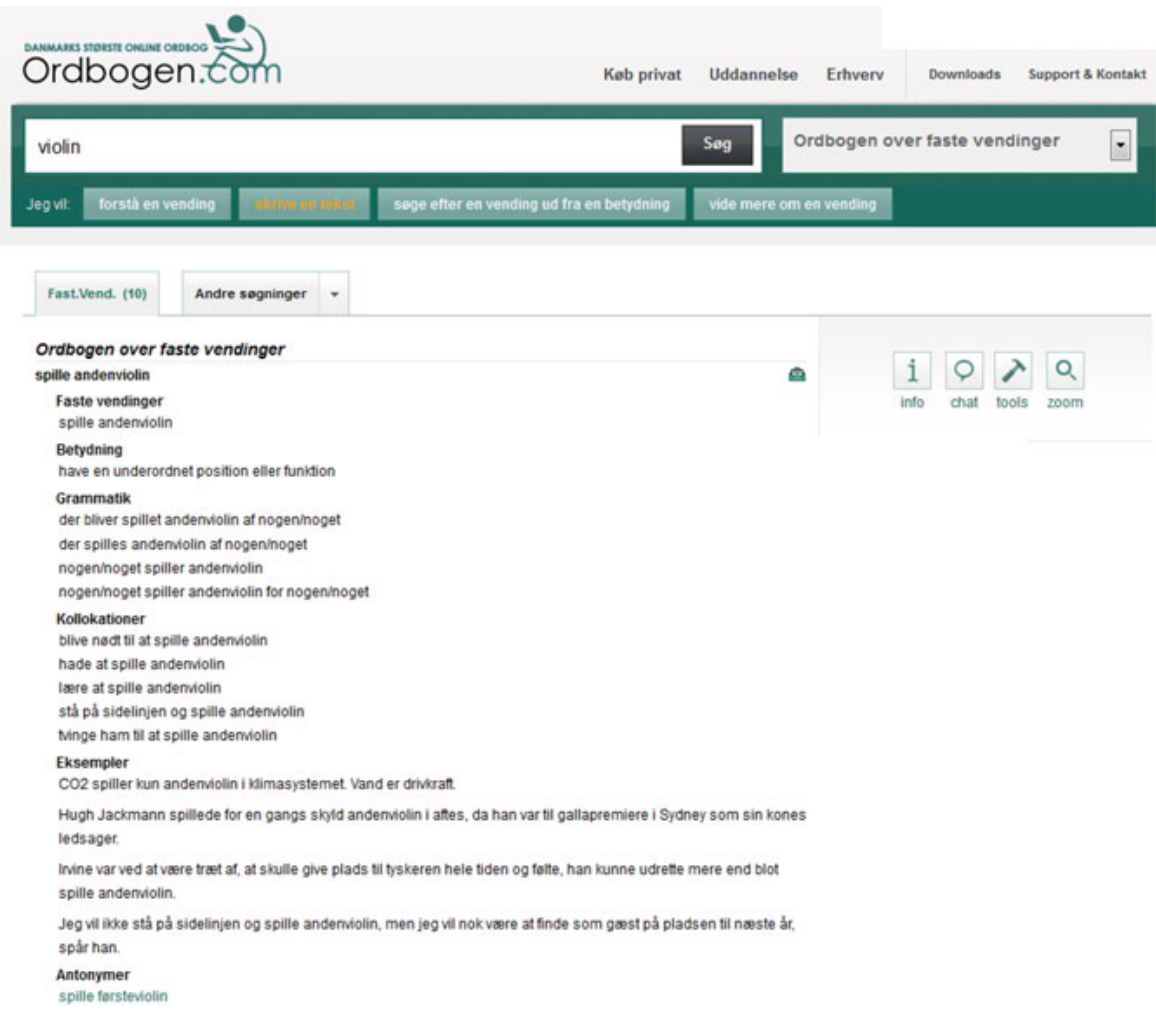

Figure 5: Text production data from the Dictionary of Fixed Expressions at Ordbogen.com 


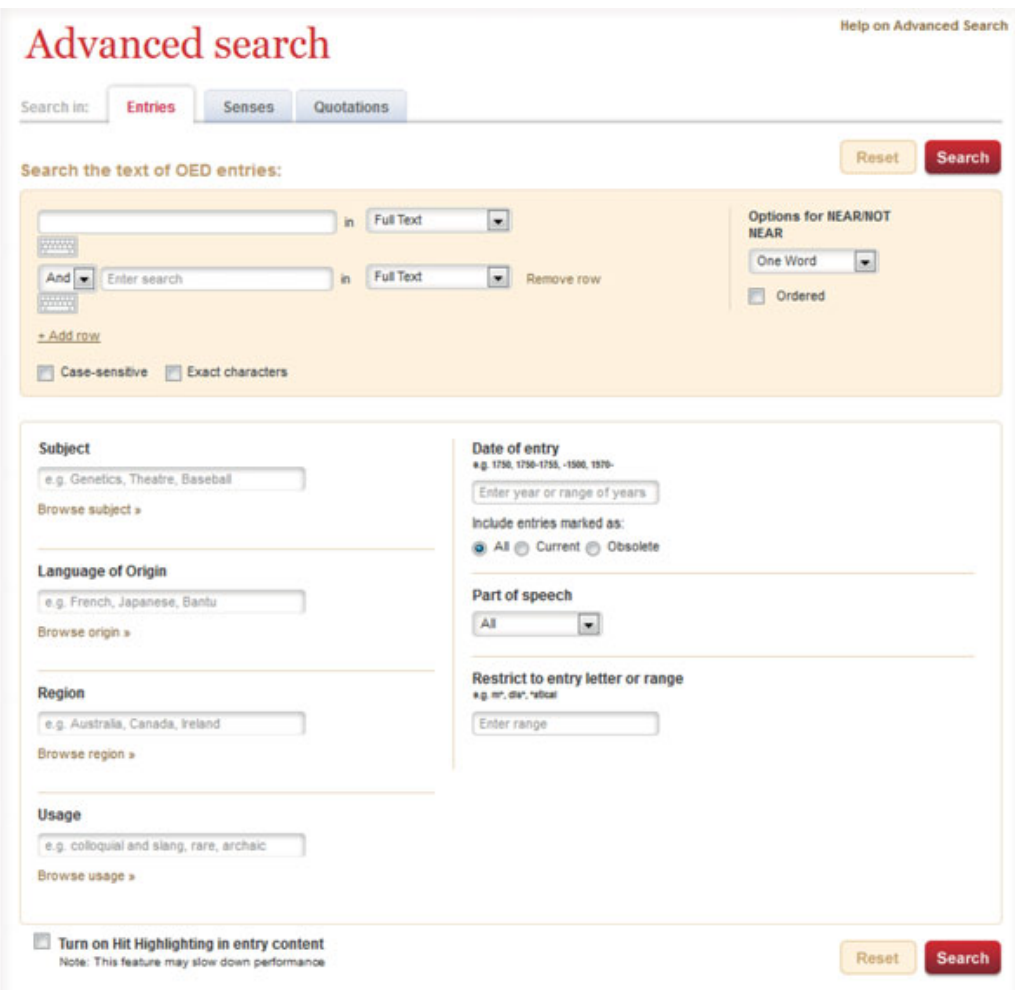

Figure 6: Advanced search interface in the Oxford English Dictionary

The advanced search interface in the Oxford English Dictionary allows the user to specify specific criteria for the search, e.g. part of speech, usage, region etc. This allows the user to refine the search further in terms of his/her specific information needs.

Once the user goes to the dictionary article itself, (s)he has the option to show or hide data, as in Figure 7.

Such devices also allow the user to limit the amount of data presented to him/ her, and thereby increase the possibility for the user to obtain data relevant at the situational and/or topical level.

The data may, however, still be too comprehensive, and the user may still be overwhelmed with data not relevant to his/her specific information need. Further filtering mechanisms may be employed, e.g. user profiling or user selection of fields to be displayed, as discussed in Bothma (2011), or even other devices, "in order to conceive dictionaries capable of meeting all the users' needs in specific types of situations" (Tarp 2009, 292).

The Base lexicale $d u$ française, developed at the Katholieke Universiteit Leuven, makes provision for this to a certain extent. For example, in a text production situa- 
Pronunciation: Brit. / rauz/, U.S. / rouz/

Forms: OE hrose (rare), OE rosæs (Northumbrian, genitive), OE (in compounds)-15 ros ... (show Hore)

Etymology: Originally < classical Latin rosa... (show Hore)

A. $n^{2}$

I. The flower or plant.

1.

a. The flower or a flowering stem of any of numerous wild and cultivated plants of the genus Rosa (see sense A. 2a); esp. the large, many-petalled flower of any of the numerous cultivated varieties of this plant, typically red, white, or yellow, and often scented, but also occurring in a wide variety of other forms and colours.

The flower has long been noted for its beauty and fragrance. The petals of the rose are used for various commercial purposes, esp. for the production of scented oil: cf.

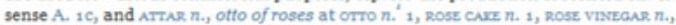
ROSE WATER $\pi .1$, etc.

The flower of the wild species typically has five petals, each with two lobes, and a characteristic sweet fragrance.

$$
\mathrm{OE}-2005
$$

b. As a mass noun: rose flowers collectively, esp. as a source of scent or flavouring; (also occas.) rose oil.

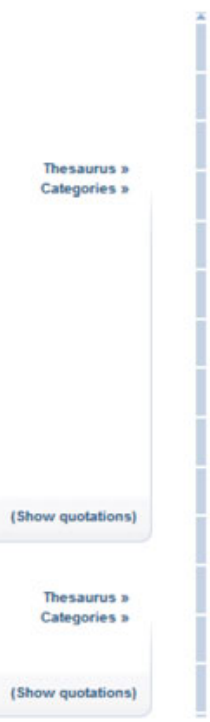

Figure 7: An illustration of the "Show more / Show less" option in the Oxford English Dictionary

tion, in writing a French text, a user may require only the plural or gender of a French word, and the user can filter the data to such an extent that only these data are displayed on screen, as in Figures 8 and 9.

These filtering mechanisms all ensure that more specific data are presented to the user in terms of his/her current information need and the data would therefore be situationally relevant - all the data are relevant in the specific situation and no additional data are presented to the user.

If the user selected the correct dictionary in terms of his/her information needs and his/her own characteristics, all data should be relevant in a cognitive situation. If this selection were to be incorrect, the data would not be cognitively relevant, e.g. in a case of a primary school child selecting a mathematics dictionary for the expert (and vice versa). See further the examples and discussion in section 3.2.1 above. The same applies to the socio-cognitive relevance criterion: if the user needed economics data from a Marxist perspective, a dictionary written with a Neoliberal bias will 


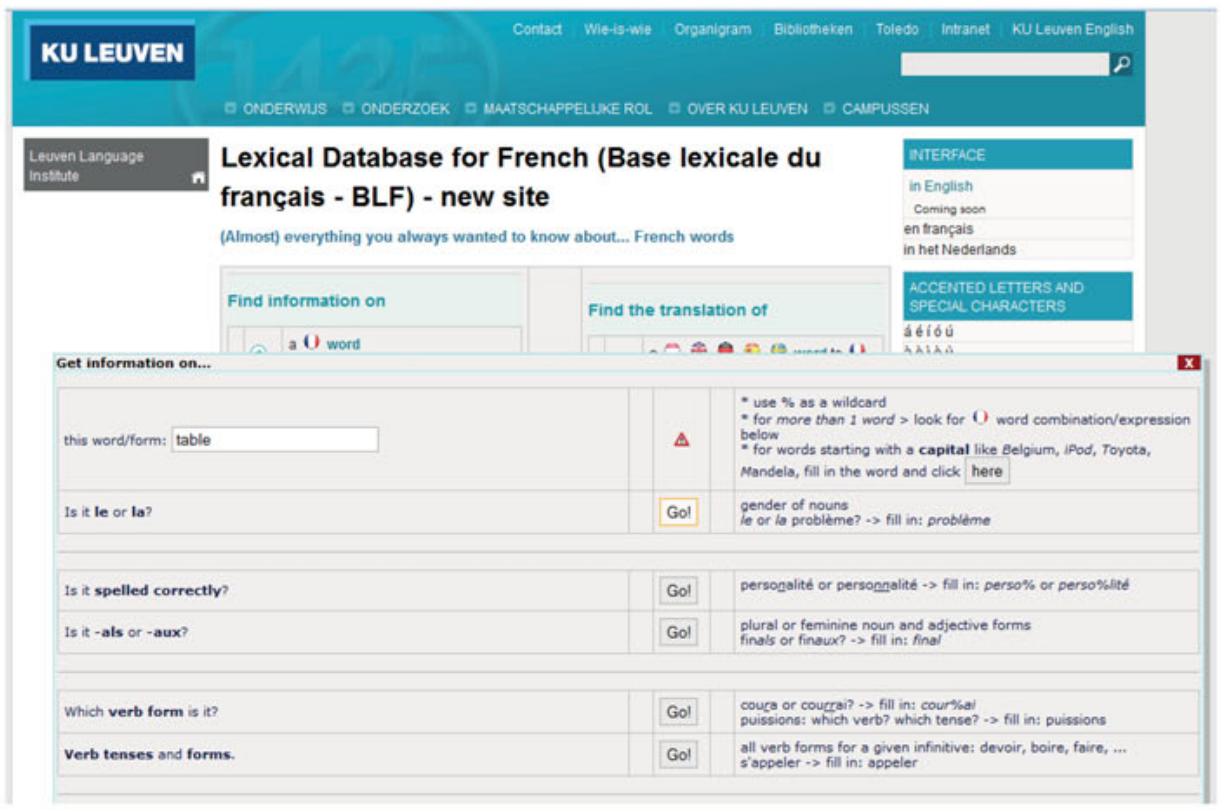

Figure 8: Obtaining grammatical data from the Base lexicale du française of the Katholieke Universiteit Leuven

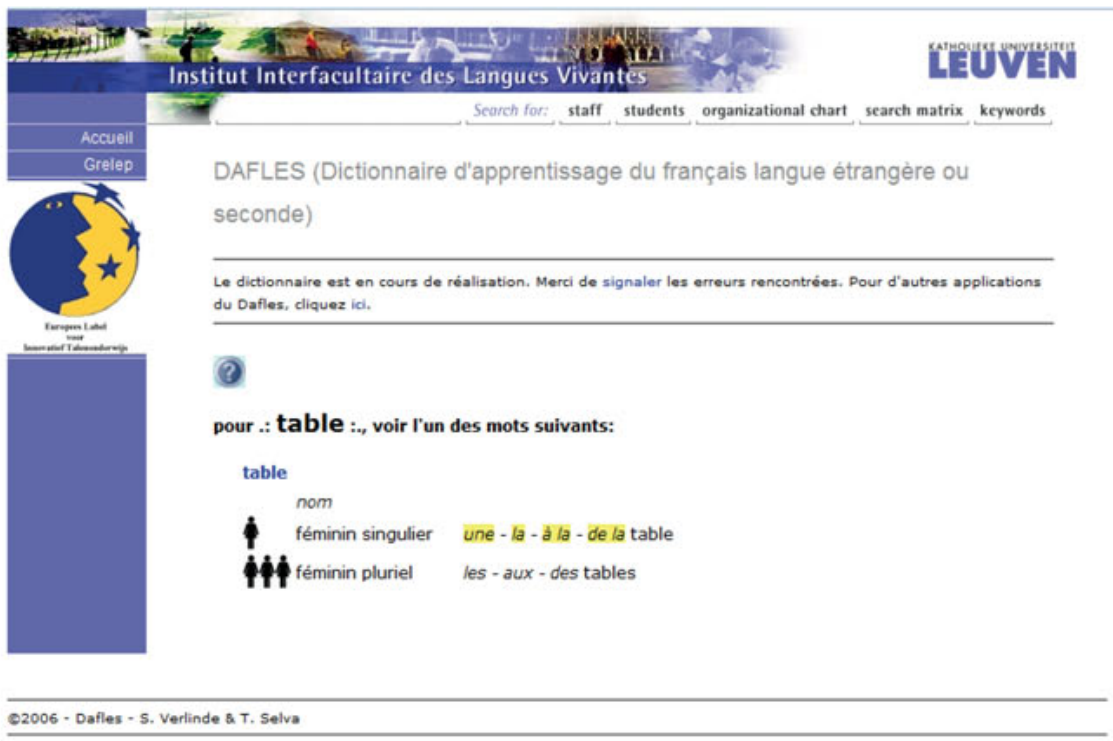

Figure 9: The data shown to the user if the search of Figure 8 is carried out 
not provide the user with data relevant from a socio-cognitive perspective, as also explained in section 3.2.1 above.

However, if the database were to be constructed in such a way that the data are marked for complexity or ideology, it would be quite feasible to have a single database from which the user could get data aimed at either a lay person (the primary school child) or an expert. Data can similarly be marked for the ideology within which the data are written, and the user could select the perspective required for his/her specific situation, and only data that conform to the set criteria and filters will be displayed. This can be done through adaptive hypermedia technologies and fine-grained markup of the data, as explained in Bothma (2011). The authors of this article are not aware of any such dictionaries. However, Bergenholtz/Kaufmann (1997) already envisaged such products when they described the Biotec-Lexinome, in which different data would be presented to different types of users; see Bergenholtz/Kaufmann (1997), especially pp. 115ff. The following quotations of definitions from Bergenholtz/ Kaufmann (1997) illustrate the principles clearly:

The first definition is aimed at the interested layman:

\section{gene}

the basic unit of inheritance transmitted from parent to offspring. An organism contains many genes - in humans approximately more than 100,000. Each gene has a specific characteristic, e.g. one out of the potential blood groups. In chemical terms genes are small sections of big complex molecules, the nucleic acids. In bacteria these are coiled aggregates and in higher organisms they are constituents of chromosomes.

$\rightarrow$ bacterium, chromosome, molecule, nucleic acid

$\rightarrow \S 3,21$

The second definition is for semi-experts:

\section{gene (Johannsen 1909)}

A gene is a DNA sequence encoding a mRNA (protein), tRNA or rRNA. For eukaryotes a gene can also be defined as a transcribed DNA sequence or transcription unit. In prokaryotes two or more proteins are often encoded in the same transcription unit, and such a transcription unit plus its associated regulatory sequences is termed an operon.

$\rightarrow$ bacterium, chromosome, molecule, nucleic acid

$\rightarrow \S 21 \mathrm{~B}$

(Definitions quoted from Bergenholtz/Kaufmann 1997, 115-116)

Constructing such information tools requires specific technology solutions which have to be made at the planning stage of the database, and also requires that the data be prepared in specific ways, both issues which are to be addressed by the lexicographer, as will be briefly mentioned in section 4. 


\subsubsection{Information retrieval}

The last action which users perform in the intra-lexicographical consultation phase is to retrieve the required information from the data resulting from the access and verification sub-phase treated in the previous section. No criterion of relevance is directly applied in this process as such, that is, not until the usefulness of the retrieved information has to be evaluated. In fact, if all the mentioned relevance criteria have been applied accordingly when selecting the information tool and accessing the data, then the retrieval should be successful and the obtained information relevant to the users' specific needs. However, the precondition for this to happen is, at the one hand, that the users, prior to the selection of the information tool, have got a correct idea of the specific type of need they experience, i.e. a correct idea in terms of the six subject relevance criteria discussed above in section 3.2.1; and on the other hand, that the appropriate information tool does exist and can be accessed properly. This not being the case, the information retrieved could represent "the right answer to the wrong question", a problem commonly known in social sciences (cf. Zikmund 1997, 96), which will also imply that the users do not get a satisfactory solution to their specific problems or needs.

\subsection{Extra-lexicographical post-consultation phase}

The value of the information retrieved in the intra-lexicographical consultation phase can only be properly evaluated when it is applied in the subsequent extra-lexicographical post-consultation phase. There are various forms of application depending on the nature of the original need. All of them can be evaluated in terms of relevance. In a cognitive situation, the information retrieved will be stored in the brain as knowledge which can be used immediately or subsequently, e.g. when preparing a lecture, a conference, a research paper, or during an examination. In a communicative situation, the information will, as a rule, be used immediately in order to solve a specific problem in terms of understanding, producing or translating a text. In an operative situation, the information will also most often be used to take immediate action, e.g. when handling a specific device, operating a machine, filling in a form, etc. And finally, in an interpretive situation, the information retrieved will be used to understand a specific sign or symbol with a view to deciding whether some action has to be taken immediately or subsequently based upon this information.

If the action - or non-action - taken in all these situations is appropriate, then the information retrieved is relevant to the satisfaction of the original need in terms of all the relevance criteria discussed above. If not, then it is irrelevant in terms of, at least, one of these criteria. However, this relevance, or irrelevance, cannot be assessed by the user alone (subjective criterion), but should also involve a third person and the use of appropriate qualitative methods (objective criterion). The user may be perfectly happy with not only the information retrieved but also the result of the subsequent 
action without being aware that it is totally unsuitable in the specific situation in question.

A Danish student, for instance, translating an expert-to-expert text on modern wind technology from Danish into Spanish, may be convinced that molino de viento is the appropriate Spanish equivalent for the Danish term vindmølle (wind turbine), although the most appropriate term to be used in this type of highly specialised text is aerogenerador, whereas molino de viento can be used in other text types addressed to laypeople, e.g. newspapers, or with reference to the monsters against which the noble Don Quixote fought his legendary battle. This is an example where the criterion of socio-cognitive relevance has not been applied properly by the student when selecting the information tool.

Another example could be a student who, during an examination, is asked where and when Napoleon died and then, based on the consultation of a historical dictionary, answers that he died in Vienna on the 22nd of July 1832 without being aware that the French emperor who died at that day was Napoleon François Charles Joseph Bonaparte, also known as Napoleon II, whereas his famous father and namesake Napoleon Bonaparte (Napoleon I), to which the question related, died on the Island of Saint Helena on the 5th of May 1821. There may be two different reasons for this mistake, the first of these being that the information tool selected does not disambiguate clearly enough between the various data resulting from the search process (i.e. Napoleon I, Napoleon II and Napoleon III), and in this case it is an example of objective irrelevance, as the problem is related to the design and functioning of the system. A second reason could be that the student - even when this disambiguation is made - does not have the necessary background knowledge allowing him or her to make use of this disambiguation and, therefore, just chooses one of the three options at random (the in-between one) without being able to place the three Napoleons in their respective historical periods. In this case, it is an example of a user not being prepared to apply the criterion of topical relevance during the data access and verification phase.

In both cases discussed above, the users themselves may be pleased by the result of the lexicographical consultation and, therefore, willing to use the information retrieved either in a Danish-Spanish specialised translation or during an examination in History. And in both cases, the well-prepared teacher or examiner will most certainly intervene and deem this positive user assessment wrong, i.e. irrelevant in terms of the original need giving rise to the lexicographical consultation. Other examples related to communicative, cognitive, operative and interpretive situations could also be provided, and they will confirm that the final evaluation of the information retrieved does not only require the user's own assessment, but also that of a third person, sometimes by means of much more sophisticated qualitative methods that the ones used above. In all cases, the various types of relevance will prove to be useful criteria for the evaluation. 


\section{Implications for the lexicographer}

As pointed out in the beginning of section 2, the lexicographical process can be approached from both the user's and the lexicographer's perspective, although the basis of all lexicographical work is ultimately the user's needs. The two types of process are interwoven, with various intersections and meeting points relevant both to lexicographical theory and practice. In this section, as a means of conclusion, we will briefly consider the implications which the previous discussion may have for the lexicographer when planning and compiling a dictionary or any other kind of information tool, as well as when teaching dictionary culture and reference skills. In this conceptual and practical work, the various criteria of relevance are relevant to all decisions and actions to be taken by the lexicographer. However, before looking closer at this relation between relevance theory and the lexicographer's work, it is appropriate to recall that the function theory operates with two different categories of user need: 1) those originally giving rise to the consultation, and 2) those related to the consultation, i.e. to the use of the information tool selected, cf. Tarp (2008). As will be seen, this basic categorisation of user needs fits perfectly into the various types of relevance criterion. Thus, in the following we will take different criteria of relevance in an order matching the lexicographer's work process.

Topical relevance. The first decision to be taken - and normally the first one taken - when preparing a lexicographical tool, is the topic to be covered by this tool. This topic could be a language (general or specialised), a specific linguistic category (e.g. idioms, collocations, and slang), a specific subject field (such as economics, archaeology, and mathematics), etc. Once the topic has been defined, it is the lexicographer's job to ensure that it is actually covered, both at a macro level (primarily in terms of the selected lemmata), and at a micro level, i.e. their treatment and presentation to the users in order to avoid misunderstandings like leaf (noun) versus leave (verb), as we saw in section 3.2.2, in the example from the dictionary used by Kindle e-books.

Cognitive relevance. The second decision to be taken in a dictionary project is to determine the target user group as well as the relevant cognitive characteristics of this group. This could be adult users or school children and students of various grades and different ages; it could be users with an academic background or the general public; it could be foreign-language learners at a beginner's, intermediate or advanced level; or it could be laypeople, semi-experts or experts within a given subject field. In all these cases, the lexicographer must adapt the dictionary to the characteristics of the specific type of target user both at a macro level (number and types of lemmata to be presented), and at a micro level (amount and types of data addressed to the lemmata as well as the presentation in all aspects). The Oxford Primary Illustrated Maths Dictionary, mentioned in section 3.2.1, is an example of such a well-adapted dictionary.

Situational relevance. The third decision which a lexicographer should take but which is frequently not taken with the necessary accuracy - is to determine the extra-lexicographical user situation(s) to be covered by the dictionary. This is abso- 
lutely imperative in order to detect and meet the users' real needs, as the nature of these needs does not only depend on the users' personal characteristics but also, and mainly, on the type of situation where they occur. A user with a text-production problem does not have the same needs as a user with a text-reception problem, and so on. Consequently, the lexicographer has to select, prepare and present different types of data in order to serve the users in each situation separately, as it has been done in the examples taken from the Danish Music Dictionary and Dictionary of Fixed Expressions, respectively, and shown in Figures 4 and 5 in section 3.2.2. If a specific e-dictionary is conceived to cover more than one extra-lexicographical situation, then it is highly advisable that the lexicographer makes provision for differentiated search options allowing the users to access only the data needed in each situation; if not, the danger of information overload and, hence, bad user service would be imminent. Situational relevance affects the macro level, where it requires differentiated lemma-selection principles (cf. Gouws/Tarp 2008), as well as the micro level, where it determines the data types to be addressed to the selected lemmata.

Socio-cognitive relevance. The fourth decision to be taken when planning and compiling a lexicographical tool is related to the socio-cognitive level of the lemmata and data to be made available by the tool. In section 3.2.1, various relevant examples were discussed. For instance, in a general dictionary for text-production purposes it is important to mark vulgar, low-style and high-style words and expressions, among others, with a view to avoiding that the users employ these words and expressions in the wrong social context, e.g. when addressing the Nobel Committee. Similarly, in a specialised dictionary, it is recommendable to mark the terms accordingly when different terms are used in expert-to-expert and expert-to-layman communication, as illustrated with the two Spanish wind-technology terms aerogenerador and molino de viento. Moreover, in a cognitive dictionary of economics, it should be compulsory to explain to its potential users whether the definitions and explications are based on a Marxist, Keynesian, Neoliberal or any other school of economics. Finally, the South African Oxford Mathematics Dictionary showed the importance of taking into account the national curriculum when preparing a dictionary of this nature for school children in a particular country. Many other examples could be listed; all of them showing that it may be advisable and even compulsory for the lexicographer to connect extra-lexicographically to style, ideology, curriculum as well as other socio-cognitive phenomena of relevance. If this is not done, the lexicographer could create various kinds of problem for the target users. As can be seen, this is once more valid both at a macro and a micro level.

Functional relevance. Thus far we have discussed four criteria of relevance related to the original user needs and their satisfaction. Now we will look at two further criteria which have to do with the users' needs in relation to the lexicographical process and the tool employed in this process. In section 3.2.1, it was briefly discussed why it is also relevant for the users that the selected information tool is easy to handle, and that the time it takes to match search queries and provide the data most likely 
to meet the users' original needs should be as short as possible. In this regard, it is indispensable that the information tool is carefully adapted to the users' lexicographical knowledge and skills in terms of its functionality and usability. The lexicographer should not expect too much from the users. Their existing dictionary culture and reference skills should be sufficient to handle the tool. With the possible exception of school children, no additional lexicographical training of the users should be required. It should, therefore, be considered part of the responsible lexicographer's job to prepare clear and detailed instructions to the system programmer requiring that the lexicographical database and user interface are as functional and user-friendly as possible in terms of the specific target user group.

Affective relevance. In section 3.2.1 we saw how the users' personal taste, individual preferences and liking may influence the selection of information tool and the way it is used. This is a difficult area to enter because it is very subjective and may express itself in multiple ways, although fashion also plays an important role. However, whatever the difficulties in this respect, it is vital that users feel comfortable when operating the tool. Hence, the lexicographer should not ignore this phenomenon or regard it as something irrelevant to lexicography. It could, therefore, be recommended to make allowance for a certain degree of individualisation of the information tool, both in terms of its user interface and functionality. This would make the tool more attractive in the eyes of its users, who would probably pay back by consulting it even more often. Various steps could be taken towards such an individualisation, some of them simpler than others, and some of them already known from various online tools. One simple step would be to allow users to change the type and size of the fonts used both at a meta-level and to display the data. Similarly, users could also be given the option to change the colours used on the interface and adapt them more to their personal taste. A further step could be that the users were allowed to hide certain disturbing items, e.g. unnecessary publicity or user instructions already read and assimilated. In section 3.2.2, some examples of interfaces allowing for various search options and access routes were shown and discussed; this is also a relevant step in order to adapt the tool to its users' personal preferences. Finally, a more complex step could be that advanced users were allowed to design their own article structure by reorganising the data fields appearing on the screen, cf. Tarp (2011; 2012). The technology required to take these and other relevant steps does already exist; it is only a question of applying it with a view to producing information tools adaptable to their users' individual taste, preferences and liking. Once more, providing pertinent instructions to the system programmers, as well as the web designers, should be considered part and parcel of the 21st century lexicographer's job. This is especially important in terms of the database design and the specifications of the required granularity of the data to enable filtering and customising the data shown to the user in a given situation for a specific information need; cf. Bothma (2011).

The above discussion gives proof to the title of this article, namely that relevance theory is relevant to lexicography; it helps to identify new tasks and responsibilities 
of the modern lexicographer, i.e. the one that considers dictionaries to be utility tools which should take advantage of all relevant technology in order to meet the users' multiple information needs and other pertinent demands. However, there is another dimension of the lexicographical work which should not be forgotten, namely the lexicographer's role in cultivating and improving the users' dictionary culture. Also in this respect, relevance seems to be extremely relevant. The six criteria of relevance discussed in this article represent an interesting framework for teaching dictionary culture and reference skills. If these criteria are taken and explained one by one, in the right order, they will point to an easily applicable methodology, not only of teaching, but also of learning dictionary culture and reference skills.

As we have seen in section 2, the lexicographical process from the user's perspective starts in the pre-consultation phase when the user becomes aware of a lexicographically relevant information need, and continues in the consultation phase where the user first has to select the most appropriate information tool, and then access and verify the data expected to meet his/her need. In this respect, the process may derail in all instances of relevance treated in section 3. It is, therefore, important that the users get a good grasp of these, as well as the order in which they should be treated:

- Topical relevance: The users most commonly know what they are dealing with, but they should also learn that this topic is a relevant criterion when selecting an information tool or verifying the data provided. They should, so to say, learn to place themselves in the right universe, not only at a macro level but also at a micro level.

- Cognitive relevance: The users - or their parents - should have a realistic idea of their own - or their children's - level of knowledge and skills: child or adult, layperson or expert, beginner or advanced, student or graduate. They - or their parents - should take this level as another relevant criterion in order to select the right tool.

- Situational relevance: Most users know in which situation - or in relation to which task - their needs occur, but they should also be aware that this is an essential criterion, both to select the most appropriate tool and to verify the data furnished by the tool.

- Socio-cognitive relevance: The users should learn that this may be another relevant criterion in terms of ideology, national curriculum, style and other socio-cognitive phenomena, both when selecting the tool and applying the retrieved information.

- Functional relevance: Users should select information tools which are easy to handle and quick to respond to their needs; if it is an online tool, then they should not only check the tool itself but also how it works on their particular Internet connection.

- Affective relevance: Users should learn that the previous criteria are the most important because they are all related to the quality of the tool and its data. But if quality is guaranteed, and they have the choice between two or more options in terms of tool, interface or search method, then they should choose the option with which they feel most comfortable from a personal point of view. 
If users of information tools assimilate the six relevance criteria listed above, they will undoubtedly take an important step towards a higher lexicographical culture which will help them to benefit even more from these tools. In this respect, relevance theory appears once more relevant to lexicography. This is exactly what we have intended to show with this article. It has been highly interesting to see how two theories - relevance theory and function theory - developed separately in the framework of two different disciplines - information science and lexicography, respectively - have so many similarities and fit so well into each other. Both theories, and disciplines, have much to learn from and contribute to each other. This article has mainly focussed on what lexicography can learn from relevance theory, and this is quite a lot; but it has also shown that lexicography in general, and function theory in particular, have at least something interesting to contribute, namely the criterion of functional relevance, which will surely be relevant when applied in the framework of information science. It is frequently in the edge between two different disciplines that new ideas are born. This is what happened here.

\section{Literature}

\subsection{Information tools}

Algemeen Nederlands Woordenboek = Schoonheim, Tanneke (ed.): Algemeen Nederlands

Woordenboek. INL Schatkamer van de Nederlandse taal, 2013. Online: 〈anw.inl.nl>.

Base lexicale du française $=$ Verlinde, Serge / Peeters, Geert / Wielandts, Joeri: Base lexicale du française. Katholieke Universiteit Leuven, 2013. Online: <ilt.kuleuven.be/blf/>.

Concise Oxford Dictionary of Archaeology = Darvill, Timothy: The Concise Oxford Dictionary of Archaeology. Second Edition. Oxford, New York: Oxford University Press, 2008.

Concise Oxford English Dictionary = Stevenson, Angus / Waite, Maurice (eds.): Concise Oxford English Dictionary. Twelfth Edition. Oxford: Oxford University Press, 2011.

Concise Oxford Dictionary of Mathematics = Clapham, Christopher / Nicholson, James: The Concise Oxford Dictionary of Mathematics. Fourth edition. Oxford: Oxford University Press, 2009. Online: 〈www.oxfordreference.com>.

Dictionary of Fixed Expressions = Bergenholtz, Henning (ed.) in cooperation with Esben Bjærge and Richard Almind: Ordbogen over Faste Vendinger. 2009. Online: 〈www.ordbogen.com〉.

Historische woordenboeken op internet $=$ Historische woordenboeken op internet. Instituut voor Nederlandse Lexicologie, 2010. Online: 〈gtb.inl.nl/>.

Macmillan Dictionary = Macmillan Dictionary and Thesaurus Free English Dictionary Online. [Online: www.macmillandictionary.com]

Music Dictionary = Bergenholtz, Inger (ed.) in cooperation with Richard Almind and Henning Bergenholtz: Musikordbogen. 2010. Online: 〈www.ordbogen.com>.

New Palgrave Dictionary of Economics = Durlauf, Steven N. / Blume, Lawrence E. (eds.): The New Palgrave Dictionary of Economics. Basingstoke, New York: Palgrave Macmillan, 2008. Online: <www.dictionaryofeconomics.com>.

Ordbogen.com = Ordbogen.com. Online: 〈www.ordbogen.com〉.

Oxford Dictionary of English = Soanes, Catherine / Stevenson, Angus (eds.): Oxford Dictionary of English. Second edition, revised. Oxford: Oxford University Press, 2010. 
Oxford Dictionary of Economics = Black, John / Hashimzade, Nigar / Myles, Gareth: Oxford Dictionary of Economics. Oxford: Oxford University Press, 2013. Online: <www.oxfordreference. com>.

Oxford English Dictionary = Simpson, John (ed.): Oxford English Dictionary. Oxford: Oxford University Press, 2012. Online: 〈www.oed.com>.

Oxford Mathematics Dictionary = Tapson, Frank / van der Vlugt, Julie / Potgieter, Rika: Oxford Mathematics Dictionary. Grades 10-12. Cape Town: Oxford University Press Southern Africa, 2013.

Oxford Primary Illustrated Maths Dictionary = Oxford Primary Illustrated Maths Dictionary. Oxford: Oxford University Press, 2013.

Oxford Reference $=0 x$ ford Reference. Online: $\langle w w w . o x f o r d r e f e r e n c e . c o m\rangle$.

Universal Dictionary of Trade and Commerce $=$ Postlethwayt, Malachy: The Universal Dictionary of Trade and Commerce. The Fourth Edition. London: W. Strahan, J. and F. Rivington, J. Hinton, 1774.

Webster's Third New International Dictionary of the English Language = Gove, P.B.: Webster's Third New International Dictionary of the English Language. Springfield, Massachusetts: MerriamWebster, 1961.

Woordeboek van die Afrikaanse Taal = Woordeboek van die Afrikaanse Taal. Online: $<w w w$. woordeboek.co.za>.

\subsection{Other literature}

Bergenholtz/Bothma 2011 = Bergenholtz, Henning / Bothma, Theo J.D.: Needs adapted data presentation in e-information tools. In: Lexikos 21. 2011, 53-77.

Bergenholtz/Gouws (2007) = Bergenholtz, Henning / Gouws, Rufus H.: Korrek, volledig, relevant. Dít is die vraag aan leksikografiese definisies. In: Tydskrif vir Geesteswetenskappe 47/4. 2007, 568-586.

Bergenholtz/Kaufmann 1997 = Bergenholtz, Henning / Kaufmann, Uwe: Terminology and lexicography. A critical survey of dictionaries from a single specialised field. In: Hermes, Journal of Linguistics 18. 1997, 91-125.

Bergenholtz/Tarp 2002 = Bergenholtz, Henning / Tarp, Sven: Die moderne lexikographische Funktionslehre. Diskussionsbeitrag zu neuen und alten Paradigmen, die Wörterbücher als Gebrauchsgegenstände verstehen. In: Lexicographica 18. 2002, 253-263.

Bergenholtz/Tarp 2003 = Bergenholtz, Henning / Tarp, Sven: Two opposing theories: On H.E. Wiegand's recent discovery of lexicographic functions. In: Hermes, Journal of Linguistics 31. 2003, 171-196.

Bothma $2011=$ Bothma, Theo J.D.: Filtering and adapting data and information in the online environment in response to user needs. In: Fuertes-Olivera, Pedro / Bergenholtz, Henning (eds.): e-Lexicography: The Internet, Digital Initiatives and Lexicography. London / New York: Continuum, 2011, 71-102.

Bothma/Prinsloo $2013=$ Bothma, Theo J.D. / Prinsloo, Danie J.: Automated dictionary consultation for text reception: a critical evaluation of lexicographic guidance in linked Kindle e-dictionaries. In: Lexicographica 29. 2013, 165-198.

Bothma/Tarp 2012 = Bothma, Theo J.D. / Tarp, Sven: Lexicography and the relevance criterion. In: Lexikos 22. 2012, 86-108.

Cosijn $2003=$ Cosijn, Erica: Relevance Judgements in Information retrieval. Unpublished DPhil thesis. Pretoria: University of Pretoria, 2003. 
Cosijn/Bothma 2005 = Cosijn, Erica / Bothma, Theo J.D.: Contexts of Relevance for Information Retrieval System Design. In: Crestani, Fabio / Ruthven, lan (eds.): Context: Nature, Impact, and Role. 5th International Conference on Conceptions of Library and Information Sciences, CoLIS 2005. Glasgow, UK, June 4-8, 2005. Berlin / Heidelberg: Springer, 2005, 47-58.

Cosijn/Ingwersen $2000=$ Cosijn, Erica / Ingwersen, Peter: Dimensions of Relevance. In: Information Processing and Management 36. 2000, 533-550.

Fuertes-Olivera/Tarp 2014 = Fuertes-Olivera, Pedro A. / Tarp, Sven: Theory and practice of specialised online dictionaries: Lexicography versus terminography. Berlin / New York: De Gruyter, 2014.

Gouws 2013 = Gouws, Rufus H.: Establishing and developing a dictionary culture for specialised lexicography. In: Jesenšek, Vida (ed.): Specialised lexicography. Print and digital, specialised dictionaries, databases. Berlin / Boston: De Gruyter, 2013, 51-62.

Gouws/Tarp 2008 = Gouws, Rufus H. / Tarp, Sven: A lexicographic approach to language policy and recommendations for future dictionaries. In: Lexikos 18. 2008, 232-255.

Hock 2012 = Hock, Randolph: Search engines. In: Bates, Marcia J. (ed.): Understanding information retrieval systems: management, types, and standards. CRC Press / Auerbach Publications, 2012.

Hausmann 1989 = Hausmann, Franz J.: Die gesellschaftlichen Aufgaben der Lexikographie in Geschichte und Gegenwart. In: Hausmann, F.J. / Reichmann, O. / Wiegand, H.E. / Zgusta, L. (Hrsg.): Wörterbücher. Dictionaries. Dictionnaires. An International Encyclopedia of Lexicography. Berlin / New York: De Gruyter, 1989 (Handbücher zur Sprach- und Kommunikationswissenschaft 5.1), 1-19.

Ingwersen/Järvelin 2005 = Ingwersen, Peter / Järvelin, Kalervo: The Turn: Integration of Information Seeking and Retrieval in Context. Dordrecht: Springer, 2005.

Tarp $2008=$ Tarp, Sven: Lexicography in the Borderland Between Knowledge and Non-knowledge. Tübingen: Niemeyer, 2008.

Tarp 2009 = Tarp, Sven. Reflections on lexicographical user research. In: Lexikos 19. 2009, 275-296. Tarp 2011 = Tarp, Sven: Lexicographical and other e-tools for consultation purposes: Towards the individualization of needs satisfaction. In: Fuertes-Olivera, Pedro A. / Bergenholtz, Henning (eds.): e-Lexicography: The Internet, Digital Initiatives and Lexicography. London / New York: Continuum, 2011, 54-70.

Tarp 2012 = Tarp, Sven: Online dictionaries: today and tomorrow. In: Lexicographica 28. 2012, 253-267.

Tarp 2015 = Tarp, Sven: On the disciplinary and functional status of economic lexicography. In: Iberica 29, 2015. (Forthcoming)

Zikmund 1997 = Zikmund, William G.: Business Research Methods. Fort Worth: The Dryden Press/ London: Harcourt Brace College Publishers, 1997. 